\title{
El virus Zika: una revisión de literatura
}

\section{The Zika virus: a literature review}

Correspondencia

Ciro Maguiña Vargas

ciro.maguina@upch.pe

Recibido: 06/03/2016

Arbitrado por pares

Aprobado: 27/04/2016

\section{Citar como:}

Maguiña C, Galán-Rodas E. El virus Zika: una revisión de literatura. Acta Med Peru. 2016;33(1):35-41

\section{Ciro Maguiña ${ }^{1,2}$, Edén Galán-Rodas ${ }^{3,4}$}

1 Vicerrectorado de Investigación, Universidad Peruana Cayetano Heredia. Lima, Perú.

2 Consejo Nacional, Colegio Médico del Perú. Lima, Perú.

3 Health Innovation Fellowship, Central American Healthcare Initiative, INCAE Business School. Alajuela, Costa Rica.

4 Centro de Investigación e Innovación en Nutrición Traslacional y Salud (CIINT), Universidad Hispanoamericana. San José, Costa Rica.

\section{RESUMEN}

Presentamos una breve revisión del nuevo virus emergente en América: el virus ZIKA, por ello tocamos los principales aspectos de la historia, epidemiología, clínica, diagnóstico y control de esta dolencia. Esta enfermedad procedente de África, llega a América el 2014 y desde el 2015 se ha expandido de manera rápida y sostenida a casi todo el continente, si bien la enfermedad es de curso benigno y autolimitado, ha creado una seria preocupación, debido a que un grupo importantes de pacientes en Brasil han presentado en forma importante el síndrome de Guillain-Barré y muchas gestantes al ser expuestas al virus han presentado microcefalia con una probable asociación, por ello se ha declarado emergencia sanitaria, siendo el control de esta nueva enfermedad ligado al control del principal vector, el Aedes aegypti. Finalmente un aspecto importante en la lucha contra el virus Zika es el acceso a información práctica, por ello se presentan algunas herramientas informáticas que permita orientar al médico y al paciente en la toma de decisiones.

Palabras clave:

Virosis; Síndrome de Guillain-Barré; Microcefalia; Aedes (fuente: DeCS BIREME). 


\begin{abstract}
We present a brief review of the new emerging virus in the Americas: the ZIKA virus. For this reason we deal with the main aspects of its history, epidemiology, clinical features, diagnosis, and control. This disease originated in Africa, reached the Americas in 2014, and from 2015 it expanded quickly and steadily affecting almost the whole continent. Although most cases are benign and self-limited, its spread has created a serious concern, since an important group of patients in Brazil have developed the Guillain-Barré syndrome, and many babies from women exposed to the virus were born with microcephaly, being this occurrence described as probably associated to the Zika virus infection. For these reasons, a sanitary emergency has been declared, and the main strategy for fighting the disease is vector control, limiting the spread of Aedes aegypti. Finally, another important aspect in the fight against the Zika virus is the access to practical information, since there are some computer tools which may orient physicians and patients for decision-making.
\end{abstract}

Key words:

Virus diseases; Guillain-Barre syndrome, Microcephaly; Aedes (source: MeSH NLM).

\section{INTRODUCCIÓN}

Desde hace varias décadas han surgido en muchas partes del mundo de manera importante y creciente las denominadas enfermedades emergentes [1], así desde fines de 1940 comienzan a describirse en muchas regiones tropicales algunas enfermedades febriles desconocidas, tales como las llamadas fiebres hemorrágicas (Ébola, Lassa, Valle del Riff, Machupo, Hantavirus, Dengue, etc.). Un ejemplo de ello fue una dolencia de gran gravedad, descubierta en 1976 en África, a la que denominaron virus Ébola, detectada en Zaire y que causó una alta letalidad (88\%), en ese primer brote, el personal de Salud fue el primero en exponerse y algunos de ellos fallecieron, esta enfermedad volvió a cobrar notoriedad cuando el 2014 afectó nuevamente a miles de personas y se expandió rápidamente en Sierra Leona y Nigeria, y se temió su extensión a otras áreas vecinas, pero felizmente fue controlada $[2,3]$.

A partir de la década de 1970, América fue afectada de manera creciente y sostenida por una nueva enfermedad, el dengue, y esta posteriormente se hizo endémica en todo el continente, causando hasta hoy en día millones de enfermos y miles de muertos [4,5].

Otra nueva dolencia viral es la que causa la enfermedad del Chikungunya, este virus fue identificado inicialmente en el sudeste Tanzania en 1953, esta dolencia es endémica de África y oriunda del África Subsahariana, desde esa época pasaron pequeños brotes y luego llegó a Asia y la India, y finalmente el 2013 llega a América $[6,7]$, produciendo una gran epidemia y lo más probable es que se haga endémica. Para complicar el panorama epidemiológico de la región, desde fines del 2014 ha ingresado un nuevo virus que causa la enfermedad del Zika.

La enfermedad del Zika fue descrita en la sangre de un mono Rhesus 766 de África en abril de 1947, en un bosque conocido con el nombre de Zika en Uganda, posteriormente a través de estudios serológicos en 1952 (Uganda y República Unida de Tanzania) se detectó la infección en seres humanos, la cual en poco tiempo durante el 2015 se ha diseminado de manera importante en gran parte de América [8,9], el virus del Zika, causa una dolencia habitualmente de comportamiento benigno en las poblaciones afectadas, pero ha producido una gran alarma mundial, debido a que este virus ha causado una grave epidemia en Brasil con más de un millón de afectados, pero ha producido un nuevo fenómeno, en el que algunas gestantes expuestas al virus, podrían desarrollar microcefalia, lo cual no fue descrito en anteriores epidemias de esta enfermedad [8-11]; es por ello que la Organización Mundial de la Salud (OMS) lo ha declarado como una nueva emergencia sanitaria. Lamentablemente hasta la fecha no existe ninguna terapia antiviral ni vacuna alguna, por ello lo único que queda es controlar al mosquito trasmisor, el Aedes aegypti, dado que es este el principal vector del Zika.

\section{HISTORIA}

El virus ZIKA fue descrito por primera vez en la sangre de un mono Rhesus 766 procedente de Uganda (África) en abril de 1947, ello ocurrió cuando se estaba investigando la temida fiebre amarilla. La palabra Zika deriva del nombre de la lengua Luganda (tribu de familia bantú) la que significa área cubierta de hierbas o de vegetación; en ese año no se tuvo ningún caso humano, el segundo aislamiento del virus fue el 12 Junio 1948, procedente de un mosquito (Aedes africanus) aproximadamente a 300 metros del primer aislamiento $[8,9]$. Posteriormente se detectó la infección en seres humanos a través de estudios serológicos en 1952 (Uganda y Republica Unida de Tanzania), es recién que en 1968 se logró aislar el virus a partir de muestras humanas en Nigeria [12,14], luego estuvo confinado en África, y posteriormente surgieron algunos brotes, como el del 2007, en la Isla Yap de la Micronesia del Pacífico, donde aparecieron 189 pacientes afectados con fiebre, rash, artralgias y conjuntivitis, en los se detectaron 49 casos positivos al virus Zika y 59 probables, 
no hubo muerte alguna, ni casos graves que requirieron hospitalización [13]. Un brote ocurrido entre los años 2013-2014 se presentó en la Polinesia Francesa del Sud Pacifico, la que posee 67 islas; se estimaron 29000 casos con $29,34 \%$ de cuadro clínico [9,13-15]; hubo otros brotes en Nueva Caledonia, Islas Cook e Isla Este, lo llamativo del brote de las Islas de la Polinesia Francesa es que se detectó un incremento inusual del síndrome Guillain-Barré (73 casos) sin ninguna muerte confirmada [12-18].

El 2014 el Zika llega a América, a la Isla de Pascua, donde se tuvo un caso, este paciente natural de esta isla había viajado a una feria de arte en Tahití, a su regreso, presentó un cuadro febril y el análisis enviado a Santiago de Chile, confirmó el diagnóstico de Zika. De acuerdo con un estudio de octubre del 2015, publicado por el virólogo Didier Musso en el Centro Para la Información Biotecnológica de Estados Unidos, el Zika llegó a Isla de Pascua desde Tahití, fue durante la fiesta cultural anual pascuense, el Tapati [19].

Posteriormente el Zika llegó a Brasil [8] y por el momento no se sabe cuál es el origen del brote que afecta de manera importante a este país y se ha extendido por casi toda América Latina. En Brasil los primeros 16 casos confirmados fueron reportados el 15 de mayo, los casos ocurrieron en los estados de Bahía y Río Grande do Norte, tanto en el noreste del país, con ocho casos cada uno y la alarma cundió cuando en octubre del 2015 en Brasil surgen muchas gestantes afectadas por esta nueva dolencia que presentaron niños con microcefalia y discapacidad [8,20-25].

\section{EPIDEMIOLOGÍA}

El virus Zika pertenece a la Familia Flaviviridae, es de aspecto esférico, no se conoce el reservorio, pero se sospecha de los monos y algunos roedores $[8,9]$. La enfermedad es transmitida por el mosquito Aedes aegypti, el mismo vector del Dengue y la Chikungunya, al 29 de enero, 25 países y territorios en América han reportado transmisión local de virus (casos autóctonos): Barbados, Bolivia, Brasil, Colombia, Costa Rica, Curazao, República Dominicana, Ecuador, Guyana, El salvador, Guyana Francesa, Guatemala, Guadalupe, Haití, Honduras, Martinica, México, Nicaragua, Panamá, Paraguay, Puerto Rico, Saint Martin, Surinam, Islas Vírgenes y Venezuela $[9,11,26,27]$.

En mayo del 2015, se confirmó el primer caso autóctono en Brasil [8], para octubre 2015, las autoridades sanitarias de Brasil detectaron un inusual incremento de casos de microcefalia en el Estado de Pernambuco y otros Estados del Noreste brasilero, así al 23 enero 2016, se habían reportado por lo menos 4180 casos sospechosos de microcefalia potencialmente asociados a infección porvirus del Zika. Las autoridades sanitarias brasileñas empezaron a sospechar en noviembre, que la causa de esta multiplicación de los casos de microcefalia era probablemente la infección del virus Zika en gestantes. El 17 de noviembre, el Instituto Oswaldo Cruz detectó el virus Zika en dos mujeres embarazadas de Paraíba, cuyos fetos habían sido diagnosticados con microcefalia. El 28 de noviembre del 2015, el Instituto Evandro Chagas, de enfermedades tropicales, volvió a detectar el virus Zika en la sangre de un bebé del estado de Pará, que tenía microcefalia y otras anomalías, y que murió a los cinco minutos de nacer. Por todo ello el Ministerio de Salud de Brasil estableció por primera vez la probable relación entre el virus y la microcefalia agregó además que según análisis iniciales, el mayor riesgo por contagio a embarazadas se produce en el primer trimestre de gestación $[21,26,28]$.

Estimaciones del Ministerio de Salud-Brasil en enero del 2016, reportan en 2015 entre 497593 a 1482701 casos autóctonos, 21 estados tienen transmisión local; durante esta epidemia se reporta un inusual número de casos de microcefalia y del Síndrome de Guillain-Barré. Por ello, la Organización Panamericana de la Salud/Organización Mundial de la Salud (OPS/OMS), declaró inicialmente la alerta epidemiológica el 1 de diciembre 2015, ante el incremento de anomalías congénitas, síndrome de GuillainBarre y otras manifestaciones autoinmunes en zonas donde circula el virus Zika [15,29,30], y su posible relación con este virus, por ello la OPS/OMS recomienda a sus Estados Miembros que establezcan y mantengan la capacidad para detectar y confirmar casos de infección por el virus Zika, preparen a los servicios de salud ante una eventual demanda adicional en todos los niveles de atención sanitaria y una demanda más alta de servicios especializados para la atención de síndromes neurológicos, así como también que fortalezcan las actividades de consulta y control prenatal; por ello la directora de la OMS Margaret Chan ha señalado, "esta emergencia no es por el virus del Zika, si no por su asociación con la microcefalia y otros trastornos neurológicos como el síndrome de Guillain Barré [26,28-30]. Es una medida de precaución, no podríamos esperar a que se demuestre esa relación". Posteriormente, la OPS/OMS ha declarado la emergencia sanitaria, este PHEIC (por sus siglas en inglés, Public Health Emergency of International Concern) es "un evento extraordinario que constituye un riesgo para la salud del público de otros Estados a través de la propagación de enfermedades y podría necesitar una respuesta internacional coordinada", esto implica una situación en la que podría describirse como: grave, repentina, inusual o inesperada conlleva implicaciones para la salud pública más allá de la frontera nacional del Estado afectado, puede requerir una acción internacional inmediata[23,26,31].

En total, Colombia reporta 61393 casos de Zika desde el inicio de la circulación del virus, de los cuales 2603 fueron confirmados por laboratorio y 58790 sospechosos por clínicas, se han confirmado 1.186 mujeres embarazadas infectadas con Zika, a las que se suman 10053 casos sospechosos. Desde el inicio de la epidemia hasta el 26 de marzo, se han presentado 34 casos de microcefalia por diferentes causas y ocho están en estudios por posible relación con el Zika. Además, en el país se han notificado 401 casos de síndromes neurológicos con antecedentes compatibles con infección por Zika. De estos, 270 son enfermos del Síndrome Guillain-Barré (SGB) [30,32,33].

\section{CLÍNICA}

El virus del Zika una vez que ingresa al cuerpo se elimina por el sudor, saliva, semen, el periodo de incubación es de 3 a 7 días, el virus se trasmite por la picadura del Aedes aegypti infectado con 
el virus Zika, se ha descrito trasmisión por la trasfusión de sangre y nuevos estudios revelan la posible trasmisión sexual $[9,21,31]$.

Después que un mosquito hembra infectado por del virus Zika, pica a un humano susceptible, el periodo de incubación fluctúa entre 3-12 días, la gran mayoría de los afectados no presenta sintoma alguno y solo un $25 \%$ tiene fiebre leve, erupciones dérmicas, conjuntivitis (síntoma muy típico típica de alta prevalencia), dolores de cabeza y en las articulaciones. Estos síntomas se resuelven entre 2 a 7 días y luego el paciente se recupera ad integrum, al parecer la respuesta inmune protege de por vida, el primer paciente foráneo que llegó al Perú, tenía estos síntomas leves.

El diagnóstico diferencial del Zika incluye algunas enfermedades prevalentes en las regiones afectadas, como el Dengue, Chikungunya, Malaria, además incluye a: Leptospirosis, Influenza, Rubeola, EBV, enfermedad meningocócica, etc.[9].

En relación a las coinfecciones, el 2014 se detectó en dos pacientes de Nueva Caledonia coinfección del dengue con Zika y en otro reporte un paciente que retornó de Nigeria tuvo Dengue, Chikungunya y Malaria; en Colombia se reportó un caso de Dengue, Chikungunya y Zika [34,35].

En la epidemia de la Polinesia Francesa no se tuvo muertes, se estimó 29000 casos con $29,34 \%$ de cuadro clínico compatible [36]; entre 2013-2014, hubo otros brotes en Nueva Caledonia, Islas Cook e Isla Este. Lo llamativo del brote de las islas de la Polinesia Francesa fue que se detectó un incremento inusual del síndrome Guillain-Barré (73 casos) sin ninguna muerte confirmada. Si bien los casos de muerte de Zika son raros, se ha descrito en Brasil, y últimamente en Colombia en un paciente con enfermedad de células falciformes [27].

\section{DIAGNÓSTICO}

Todavía no se tienen test diagnósticos de buena sensibilidad y especificidad, hoy en día no se tiene una prueba estándar serológico, la prueba más empleada y usada es el PCR en sangre que es útil en la fase aguda, usada durante la primera semana de enfermedad, esta prueba se está usando en el líquido amniótico y todavía no se ha validado $[37,38]$. Lamentablemente, no se cuenta hoy en día con métodos serológicos (ELISA, Western)

\section{CONTROL Y PREVENCIÓN}

El principal objetivo es el control del vector: Aedes aegypti, el cuales el vector del dengue fiebre amarilla urbana, Chikungunya, Dengue y de esta nueva dolencia. Este mosquito está presente en más de 150 países en áreas tropicales y subtropicales $\left(45^{\circ}\right.$ latitud norte y $35^{\circ}$ latitud sur), es de hábitos antropofílicos y domésticos. Los huevos son capaces de resistir desecación y temperaturas extremas con sobrevida de 7 meses a un año, la mayor parte de cada postura es de eclosión rápida, mientras un porcentaje reducido, constituyen los llamados huevos resistentes, inactivos o residuales, capaces de largas sobrevidas; las larvas se desarrollan entre $25^{\circ} \mathrm{C}$ a $29^{\circ} \mathrm{C}$, en 5 a 7 días. El mosquito es incapaz de resistir temperaturas $<10^{\circ} \mathrm{C}$, o superiores a $44^{\circ} \mathrm{C}$ a $46^{\circ} \mathrm{C}$, impidiéndose a $13^{\circ} \mathrm{C}$ su pasaje a pupa, la cual no requiere alimentación. Entre $28^{\circ} \mathrm{C}$ a $32^{\circ} \mathrm{C}$ se transforma en adulto en 1 a 3 días, por lo tanto, cada 10 días se tiene una nueva generación de adultos. El mosquito pica principalmente durante el día, en espacios interiores como en exteriores, son más activos durante las dos primeras horas (amanecer) y varias horas antes del atardecer, pero pueden picar de noche en zonas bien iluminadas, puede picar a la gente sin que den cuenta y pica varias personas de una misma casa [39]. El mosquito Aedes aegypti, en el Perú se la ha detectado en 20 regiones, 85 provincias y 392 distritos, las regiones con mayor proliferación son Tumbes Piura, San Martín, Madre de Dios. En el Perú, la reintroducción del Aedes aegypti fue detectada en 1984 en Loreto, luego se dispersó hacia regiones vecinas como San Martín y la selva central (Satipo y Chanchamayo), en Lima se registró por primera vez en el año 2000 en cinco distritos. (La Victoria, El Agustino, Rímac, San Juan de Lurigancho y Cercado de Lima) y posteriormente se extendió a otros 26 distritos de Lima y 3 distritos del Callao. Por otro lado, la identificación de cinco haplotipos de en nuestro país nos indica que esta variabilidad genética se debería tanto a la migración activa del vector como a la migración pasiva mediada por la actividad humana [40]. Si bien el Aedes aegypti es el principal vector, pueden existir otros vectores que hay que tener en cuenta.

\section{ACCESO AINFORMACIÓNEINVESTIGACIÓN}

Con el avance de las tecnologías de información y comunicación, un aspecto importante en la lucha contra el virus Zika es el acceso a información práctica a través de herramientas informáticas que permita orientar al médico y al paciente en la toma de decisiones ante una eventual infección. Entre las organizaciones e instituciones que brindan información relevante y actualizada sobre Zika, tenemos a los Centros para el Control y Prevención de Enfermedades (CDC) [http:// www.cdc.gov/Zika/index.html], La Biblioteca Nacional de Medicina de Estados Unidos (NLM) [https://disaster.nIm.nih. gov/dimrc/Zikavirus.html\#a6], la Organización Mundial de la Salud (OMS, WHO) [http://www.who.int/emergencies/Zikavirus/en/], la Organización Panamericana de la Salud (OPS, PAHO) [http://www.paho.org/hq/index.php?option=com_ content\&view=article\&id=11585\&ltemid=41688\&lang=es], entre otras organizaciones.

Un recurso importante disponible en internet es el "Zikalnfection" (https://Zikainfection.tghn.org/) que brinda información para el intercambio de protocolos y desarrollo de la investigación en Zika, epidemiología, manejo clínico de los pacientes, así como las lecciones aprendidas sobre la respuesta al virus Zika, esta plataforma es coordinada por la Fundación Oswaldo Cruz (FioCruz), e integrada por la OMS, el Consorcio Internacional de Infecciones respiratorias Agudas Graves y Emergentes (ISARIC, por su siglas en inglés International Severe Acute Respiratoryand Emerging Infection), el Institut Pasteur International Network (IPIN), el German Centre for Infection Research, entre otras instituciones. 


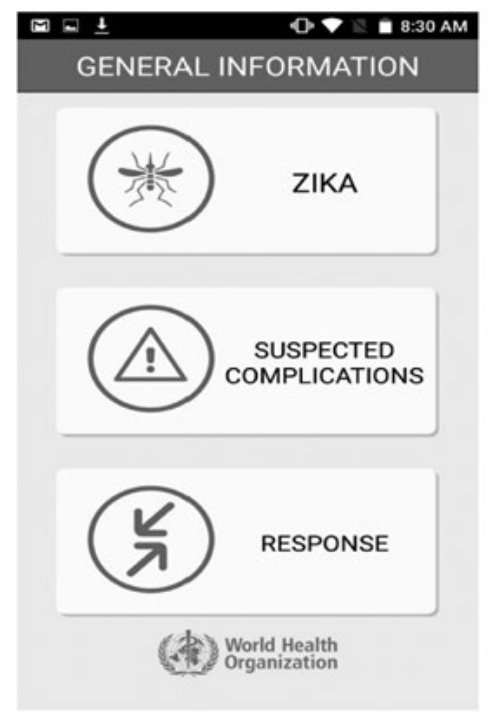

Figura 1. WHO Zika App,

Una herramienta útil para investigación es la base de datos "Zika Research" [http://www.paho.org/Zika-research/] desarrollada por la OPS que brinda acceso a los estudios científicos e investigaciones vinculadas con el Zika a nivel global, las cuales se encuentran categorizadas y organizadas de manera sistemática e incluye tanto las investigaciones ya publicadas como aquellas que se encuentran en proceso de publicación. Cada estudio se encuentra clasificado según las siguientes áreas: causalidad; manejo clínico; patogénesis de la enfermedad y consecuencias; epidemiología; sistemas de salud y respuesta de los servicios; intervenciones de salud pública; investigación y desarrollo de productos; virus, vectores y reservorios. También se puede buscar por el tipo de publicación: artículos publicados, protocolo y publicación de resultados preliminares.

Además, con el auge de las tecnologías móviles se vienen desarrollando una diversidad de aplicaciones móviles (apps) para

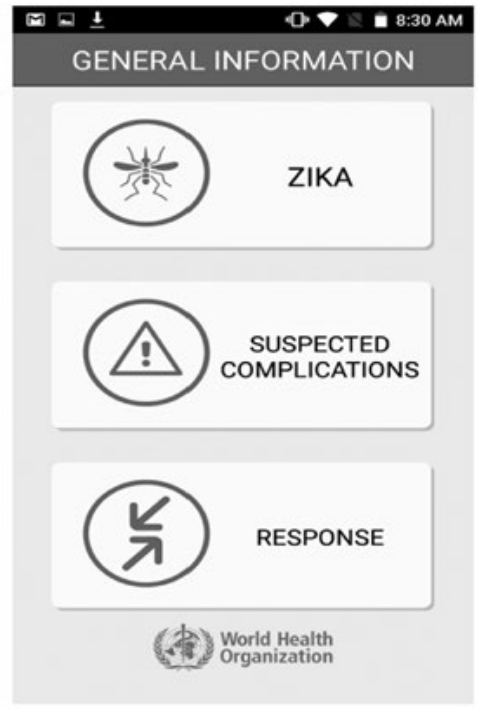

diferentes utilidades en medicina, principalmente brindando información sobre diagnóstico y prevención de enfermedades, como es el caso de "WHO Zika App" de la OMS [http://www. who.int/risk-communication/Zika-virus/app/en/], que brinda información actualizada sobre los diferentes aspectos del Zika, orientada tanto al personal de salud como a la población general. Contamos también con la app desarrollada por el Ministerio de Ciencia y Tecnología de Argentina llamada "Barrio sin dengue" (Figura 1), que permite localizar en un mapa aquellos lugares que son posibles focos de reproducción del Aedes aegypti [http://www.barriosindengue.gob.ar/]; así también, en Brasil, el Gobierno y la organización civil Colab.re han implementado la app "Sin Zika" [http://www.sinZika.org/home.htm], la cual permite a la ciudadanía compartir imágenes sobre posibles criaderos del mosquito e indicar su localización, facilitando el trabajo de las autoridades en la oportuna adopción de medidas preventivas y correctivas (Figura 2).
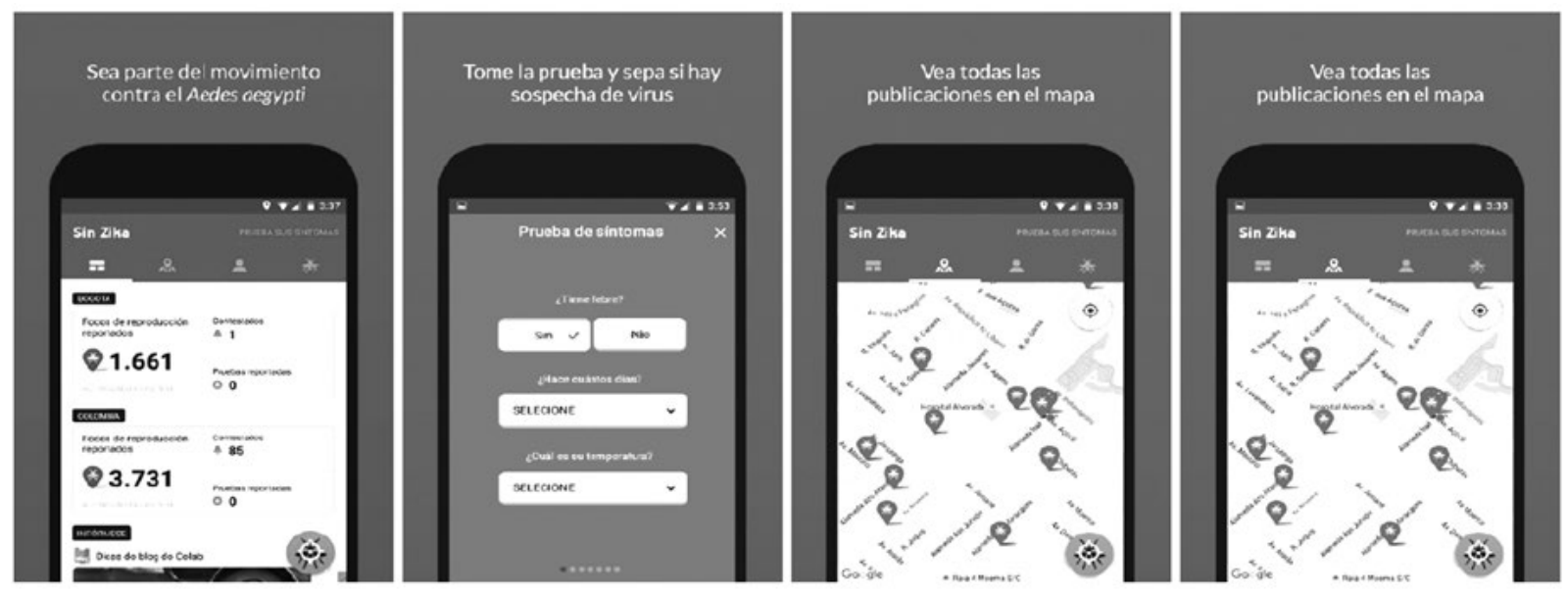

Figura 2. Sin Zika App. 


\section{COMENTARIOS FINALES}

Esta nueva enfermedad en América, tiene a una población susceptible, por ello no sabemos de su comportamiento epidemiológico en las distintas regiones y el tipo de diseminación en los diversos países, tal como está ocurriendo en Brasil y Colombia, no tenemos evidencia científica sobre la dinámica de trasmisión, carga de enfermedad, entre otras variables epidemiológicas; el tema se complica más, cuando en algunas regiones del Perú existen enfermedades endémicas como malaria, dengue, leptospirosis, enfermedad de Carrión, enfermedad meningocócica, etc., que dan cuadros similares y pueden coexistir y confundir el diagnóstico. Otro tema, es el comportamiento en las gestantes y el impacto en la salud reproductiva y los neonatos, los problemas de trasmisión vertical, el uso de los métodos anticonceptivos y el tema del aborto terapéutico y los problemas éticos que conlleva.

Fuente de financiamiento: Autofinanciado.

Conflictos de interés: los autores declaran no tener conflictos de interés con la publicación de este artículo.

\section{REFERENCIAS BIBLIOGRÁFICAS}

1. Gotuzzo E. Enfermedades emergentes y reemergentes en el Perú Rev Med Hered. 2002;13(2):37-9.

2. Maguiña C. Enfermedad por el virus del Ébola. Rev Med Hered. 2015;26:195-201.

3. Organización Mundial de la Salud. Enfermedad por el virus del Ébola. Ginebra: Organización Mundial de la Salud; 2014.

4. Organización Panamericana de la Salud. Resurgimiento del dengue en las Américas. Boletín Epidemiológico. 1997;18:1-6.

5. Maguiña C. Consideraciones sobre el dengue. Diagnóstico (Perú). 2002; 41(4):1.

6. Sourisseau M, Schilte C, Casartelli N, Trouillet C, Guivel-Benhassine $F$, Rudnicka $D$, et al. Characterization of reemerging chikungunya virus. PLoS Pathog. 2007;3(6):e89.

7. Maguiña C. Fiebre Chikungunya una enfermedad emergente de gran problema de Salud Pública. Rev Med Hered. 2015;26:55-9.

8. Zanluca C, de MeloVCA, Mosimann ALP, dos Santos GIV, dos Santos CND, Luz K. First report of autochthonous transmission of Zika virus in Brazil. Mem Inst Oswaldo Cruz. 2015;110:569-72.

9. Center for Disease Control and Prevention. Zika virus. Atlanta: Center for Disease Control and Prevention; 2016.

10. Dick GW, Kitchen SF, Haddow AJ. Zika virus Isolations and serological specificity. Trans R Soc Trop Med Hyg. 1952;46:509-20.

11. World Health Organization. Zika virus. Ginebra: World Health Organization; 2016

12. Musso D, Nilles EJ, Cao-Lormeau VM. Rapid spread of emerging Zika virus in the Pacific area. Clin Microbiol Infect. 2014;20(10): 595-6.

13. Duffy MR, Chen TH, Hancock WT, Powers AM, Kool JL, Lanciotti RS, et al. Zika virus outbreak on Yap Island. Federated States of Micronesia. N Engl J Med. 2009;360:2536-43.

14. Hayes EB. Zika virus outside Africa. Emerg Infect Dis. 2009;15:134750.
15. Oehler E, Watrin L, Larre P, Leparc-Goffart I, Lastere S, Valour F, et al. Zika virus infection complicated by Guillain-Barres syndromecase report, French Polynesia, December 2013. Euro Surveill. 2014;19:20720.

16. Musso D, NhanT, Robin E, Roche C, Bierlaire D, Zizou K. Potential for Zika virus transmission through blood transfusion demonstrated during an outbreak in French Polynesia, November 2013 to February 2014. Euro Surveill. 2014;19:20771.

17. Foy BD, Kobylinski KC, Foy JLC, Blitvich BJ, Travassos da Rosa A Haddow $A D$, et al. Probable non vector 28 borne transmission of Zika virus, Colorado, USA. Emerg Infect Dis. 2011;17:880-2.

18. Besnard M, Lastère $S$, Teissier A, Cao-Lormeau VM, Musso D. Evidence of perinatal transmission of Zika virus, French Polynesia, December 2013 and February. Euro Surveill. 2014;19:20751.

19. British Broadcasting Corporation. Chile, Isla de Pascua: Cómo convivir con el mosquito Aedes aegypti y evitar la fiebre Zika. Cordova: Servicio de Infectología Hospital Nuestra Señora de la Misericordia; 2016

20. Ministério da Saúde. Microcefalia-Ministério da Saúde divulga boletim epideiológico. Brasília: Ministério da Saúde; 2015.

21. Ministério da Saúde. Novos casos suspeitos de microcefalia são divulgados pelo Ministério da Saúde. Brasilia: Ministério da Saúde; 2016.

22. Cardoso CW, Paploski IAD, Kikuti M, Rodriguez MS, Silva MMo, Campos GS. Outbreak of exanthematous illness associated with Zika, chikungunya, and dengue viruses, Salvador. Brazil Emerg Infect Dis. 2015;21:2274-6.

23. Mlakar J, Korva M, Tul N, Popović M, Poljšak-Prijatelj M, Mraz $J$, et al. Zika virus associated with microcephaly. N Engl J Med. 2016;374:951-8.

24. Oliveira-Melo AS, Malinger $G$, Ximenes R, Szenjenfeld PO, Alves Sampaio $S$, Biospo de Filippis M. Zika virus intrauterine infection causes fetal brain abnormality and microcephaly: tip of the iceberg? Ultrasound Obstet Gynecol. 2016;47(1):6-7.

25. Schuler-Faccini L, Ribeiro EM, Feitosa IM, Horovitz DDG, Cavalcanti DP, Pessoa A, et al. Possible Association Between Zika Virus Infection and Microcephaly - Brazil, 2015. MMWR Morb Mortal Wkly Rep. 2016;65:59-62.

26. Fauci A, Morens D. Zika Virus in the Americas - Yet Another Arbovirus Threat. N Engl J Med. 2016;374:601-4.

27. Arzuza-Ortega L, Polo A, Pérez-Tatis G, López-García H, Parra $E$, Pardo-Herrera $L C$, et al. Fatal Zika virus infection in girl from Colombia. Emer Infect Dis. 2016;22(5):925-7.

28. Loos S, Mallet HP, LeparcGoffart I, GauthierV, Cardoso T, Herida M. Current Zika virus epidemiology and recent epidemics. Med Mal Infect. 2014;44:302-7.

29. European Centre for Disease Prevention and Control. Rapid risk assessment: Zika virus epidemic in the Americas: potential association with microcephaly and Guillain-Barré syndrome. Stockholm: European Centre for Disease Prevention and Control 2016

30. Brasil P, Pereira JP, Raja Gabaglia C, Damasceno L, Wakimoto M Nogueira RMR, et al. Zika Virus Infection in Pregnant Women in Rio de Janeiro: Preliminary Report. N Engl J Med. 2016;6(2).

31. Rodríguez-Morales A, Willamil-Gómez W. El reto de Zika en Colombia y América Latina: Una urgencia sanitaria internacional. Infectio. 2016;20(2):59-61.

32. Villamil-Gómez WE, Mendoza-Guete A, Villalobos E, GonzálezArismendy E, Uribe-García AM, Castellanos JE, et al. Diagnosis, Management and Follow-up of Pregnant Women with Zika virus 
infection: A preliminary report of the ZIKERNCOL cohort study on Sincelejo, Colombia. Travel Med Infect Dis. 2016;14(2):155-8.

33. Instituto Nacional de Salud. Enfermedad por virus Zika. Bogotá: Instituto Nacional de Salud, Semana epidemiológica 12 de 2016 (20 mar-26 mar). p. 89-94.

34. Raut CG, Rao NM, Sinha DP, Hanumaiah H, Manjunatha MJ. Chikungunya, dengue, and malaria co-infection after travel to Nigeria, India. Emerg Infect Dis. 2015;21(5):908-9.

35. Villamil-Gómez WE, González-Camargo O, Rodriguez-Ayubi J, Zapata-Serpa D, Rodriguez-Morales AJ. Dengue, chikungunya and Zika co-infection in a patient from Colombia. J Infect Public Health. 2016 Jan 2. pii: S1876-0341(15)00221-X.

36. Musso $D$, Nhan $T$, Robin $E$, Roche $C$, Bierlaire $D$, Zisou $K$, et al. Potential for Zika virus transmission through blood transfusion demonstrated during an outbreak in French Polynesia, November 2013 to February 2014. Euro Surveill. 2014;19(14). pii: 20761.
37. Staples JE, Dziuban EJ, Fischer M, Cragan JD, Rasmussen $\mathrm{SA}$, Cannon MJ, et al. Interim guidelines for the evaluation and testing of infants with possible congenital Zika virus infection-United States, 2016. MMWR Morb Mortal Wkly Rep. 2016;65(3):63-7.

38. Faye O, Faye O, Diallo D, Diallo M, Weidmann M, Sall A. Quantitative real-time PCR detection of Zika virus and evaluation with fieldcaught mosquitoes. Virology Journal. 2013;10:311.

39. California Department of Public Health, Division of Communicable Disease Control. Hoja Informativa sobre Aedes aegypti - (Mosquito de la Fiebre Amarilla). California: Health And Human Services Agency; 2014 .

40. Cabezas C, Fiestas V, García-Mendoza M, Palomino M, Mamani $E$, Donaires F. Dengue en el Perú: a un cuarto de siglo de su reemergencia. Rev Peru Med Exp Salud Publica. 2015;32(1):14656.

\title{
Ahora puede enviar sus artículos para Acta Médica Peruana en nuestro Open Journal System:
}

\author{
www.amp.cmp.org.pe
}

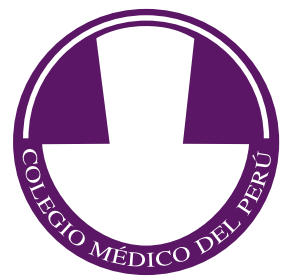

